\title{
INFLUÊNCIA DA ÉPOCA DE SEMEADURA NO CRESCIMENTO, PRODUTIVIDADE E OUTROS FATORES DE PRODUÇÃO EM CULTIVARES DE AMENDOIM NA REGIÃO DA ALTA PAULISTA ${ }^{(1)}$
}

\author{
FRANCISCO SEIITI KASAI ${ }^{(2,5)}$, EDISON MARTINS PAULO ${ }^{(2)}$, \\ IGNÁCIO JOSÉ DE GODOY ${ }^{(3)} \&$ VIOLETA NAGAI ${ }^{(4)}$
}

\begin{abstract}
RESUMO
Nos anos agrícolas 1989/90 e 1990/91, realizaram-se experimentos para estudar o crescimento, a produtividade e outros fatores de produção em quatro cultivares de amendoim estabelecidos em diversas épocas. O delineamento estatístico adotado foi o de blocos ao acaso com parcelas subdivididas, constituindo as parcelas as épocas de semeadura e as subparcelas, os cultivares IAC-Oirã, IAC-Poitara, IAC-Tupã e Tatu. Observaram-se, em todos os cultivares, decréscimos na massa seca da parte aérea, no número e na massa de vagens por planta, da primeira para a última época de semeadura, de setembro ou outubro até março. As maiores produtividades foram obtidas nas semeaduras da segunda quinzena de setembro e de outubro. Relacionaram-se os resultados à temperatura do ar. Os cultivares IAC-Oirã, IACPoitara e IAC-Tupã, na melhor época de semeadura, apresentaram maior número e massa de vagens por planta, comparativamente ao Tatu, que mostrou o maior rendimento.
\end{abstract}

Termos de indexação: amendoim, cultivares, épocas de semeadura, produtividade, crescimento, características agronômicas.

\footnotetext{
(1) Recebido para publicação em 30 de abril de 1997 e aceito em 22 de janeiro de 1999.

${ }^{(2)}$ Núcleo de Agronomia da Alta Paulista, Instituto Agronômico (IAC), Caixa Postal 191, 17800-000 Adamantina (SP).

(3) Centro de Plantas Graníferas, IAC, Caixa Postal 28, 13001-970 Campinas (SP).

(4) Pesquisadora aposentada, IAC.

${ }^{(5)}$ Com bolsa de mestrado da CAPES.
} 


\title{
ABSTRACT \\ INFLUENCE OF SOWING TIME ON GROWTH, PRODUCTIVITY AND OTHER YIELD CHARACTERS OF PEANUT CULTIVARS IN THE ALTA PAULISTA REGION, STATE OF SÃO PAULO, BRAZIL
}

\begin{abstract}
Field experiments were carried out during the crop growing seasons of 1989/90 and 1990/91 in Adamantina, State of São Paulo, Brazil. The objective was to study the influence of sowing time on growth, yield and other agronomic yield characters of four peanut cultivars under the agroecological conditions of the Alta Paulista. The study used a split-plot experimental design with six randomized blocks. The main plots were sowing times whereas the subplots were the cultivars IAC-Oirã, IAC-Poitara, IAC-Tupã and Tatu. Decrease in dry matter yield, pod number and yield per plant were observed in all cultivars, from the first to the last sowing date, i.e., from September /October through March, respectively. The experimental results were related to the air temperature. The greatest pod yields were achieved when peanuts were sowed between late September and October. The cultivars IAC-Oirã, IAC-Poitara and IAC-Tupã showed greater pod number and dry matter yield per plant than the cv. Tatu.
\end{abstract}

Index terms: peanut, cultivars, sowing times, yield, growth, agronomic yield characters.

\section{INTRODUÇÃO}

A planta do amendoim não é sensível ao fotoperíodo, necessitando, para ótimo desenvolvimento, temperatura média entre 22 e $29^{\circ} \mathrm{C}$ e 500 a $700 \mathrm{~mm}$ de chuva da semeadura à colheita (Reichardt, 1987).

Nas condições tropicais, estudos de épocas de semeadura de amendoim têm mostrado que as maiores produtividades são conseguidas com a implantação da cultura no início do ano agrícola (Smartt, 1961, 1964; Marenah \& Anderson, 1977) e que os piores resultados acontecem com o semeio da oleaginosa em março (Canecchio Filho, 1955; Wessling, 1966).

No Estado de São Paulo, a recomendação da época de semeadura do amendoim não leva em consideração as especificidades climáticas das diferentes regiões, indicando-se, generalizadamente, os meses de setembro ou outubro e fevereiro, como os mais apropriados para a implantação respectiva do amendoim "das águas" e "da seca" (Godoy et al., 1986). Considerando-se, contudo, que a implantação da cultura é dependente, sobretudo, da umidade do solo, as condições térmicas e hídricas ideais citadas por Reichardt (1987) podem não ocorrer em muitas lavouras de amendoim estabelecidas durante o ano agrícola.

Temperaturas superiores a $31^{\circ} \mathrm{C}$ diminuem o número de vagens (Bolhuis \& Groot, 1959; Leong \& Ong, 1983; Ketring, 1984; Ong, 1984), a massa de vagens (Bolhuis \& Groot, 1959; Ong, 1984), a massa de grãos por planta (Ketring, 1984) e o acúmulo de matéria seca pelo amendoim (Bolhuis \& Groot, 1959; Ketring, 1984; Ong, 1984).

A água pode interferir no estabelecimento da cultura, reduzindo a população de plantas (Canecchio Filho, 1955), a massa de cem grãos e o rendimento (Pallas et al., 1979).

Sabe-se, também, que a época de semeadura pode influenciar o índice de colheita, o acúmulo de matéria seca da parte aérea e a massa de vagens (Zade et al., 1985), o número de vagens por planta (Ketring, 1984) e a qualidade do amendoim (Smartt, 1964).

Variedades de amendoim podem apresentar, quando semeadas na mesma data, diferentes produtividades (Canecchio Filho, 1955; Wessling, 1966; Zade 
et al., 1985, Pompeu, 1987), massa de cem grãos (Pompeu, 1987), índice de colheita e acúmulo de matéria seca (Zade et al., 1985).

O presente trabalho objetivou estudar o comportamento, o crescimento, a produção e as qualidades agronômicas de quatro cultivares de amendoim submetidos a diferentes épocas de semeadura nas condições da Alta Paulista.

\section{MATERIAL E MÉTODOS}

O estudo foi realizado no Núcleo de Agronomia da Alta Paulista, do Instituto Agrônomico, em Adamantina (SP), entre a primavera e o outono de $1989 / 90$ e 1990/91.

Adotou-se o delineamento estatístico de blocos ao acaso com parcelas subdivididas e seis repetições, correspondendo às parcelas as épocas de semeadura e às subparcelas, os cultivares de amendoim IAC-Oirã, IAC-Poitara, IAC-Tupã e Tatu. As parcelas foram constituídas por 24 linhas com 5,0 m de comprimento e espaçadas entre si de $0,6 \mathrm{~m}$ e as subparcelas, pelo conjunto de seis linhas consecutivas, contendo um dos cultivares de amendoim, considerando-se úteis as quatro linhas centrais das subparcelas.

Em 1989/90 e 1990/91 houve, respectivamente, oito e nove datas de semeadura (Quadro 1), efetuando-se, para cada uma delas, preparo exclusivo do solo mediante aração e gradagem. Semeou-se o amendoim manualmente, depositando-se 16 a 20 sementes por metro de sulco previamente adubado com $80 \mathrm{~kg}$ / ha de $\mathrm{P}_{2} \mathrm{O}_{5}$ e $30 \mathrm{~kg} /$ ha de $\mathrm{K}_{2} \mathrm{O}$. Anotou-se a população inicial das plantas das subparcelas no desbaste, entre 15 e 20 dias da semeadura, deixando-se dez plantas por metro linear. Excepcionalmente, por problemas de estiagem, a densidade de plantas nas parcelas semeadas na primeira época do primeiro ano do ensaio foi reduzida para cinco-seis plantas por metro. $\mathrm{O}$ tratamento fitossanitário dos experimentos seguiu as recomendações de Godoy et al. (1986).

Na colheita, coletaram-se, ao acaso, vinte plantas em cada subparcela, determinando-se a massa
Quadro 1. Épocas e respectivas datas de semeadura de quatro cultivares de amendoim semeados em oito e nove épocas, respectivamente, nos anos agrícolas 1989/90 e 1990/91 em Adamantina (SP)

\begin{tabular}{|c|c|c|}
\hline \multirow{2}{*}{$\begin{array}{l}\text { Épocas de } \\
\text { semeadura }\end{array}$} & \multicolumn{2}{|c|}{ Datas de semeadura } \\
\hline & $1989 / 90$ & 1990/91 \\
\hline $1 \ldots \ldots \ldots \ldots$ & $27 / 09 / 89$ & $15 / 10 / 90$ \\
\hline $2 \ldots \ldots \ldots \ldots \ldots$ & $13 / 11 / 89$ & $06 / 11 / 90$ \\
\hline $3 \ldots \ldots \ldots \ldots$ & $28 / 11 / 89$ & $06 / 11 / 90$ \\
\hline $4 \ldots \ldots \ldots \ldots$ & $14 / 12 / 89$ & $07 / 12 / 90$ \\
\hline $5 \ldots \ldots \ldots \ldots$ & $28 / 12 / 89$ & $17 / 12 / 90$ \\
\hline $6 \ldots \ldots \ldots \ldots$ & $16 / 01 / 90$ & $04 / 01 / 91$ \\
\hline $7 \ldots \ldots \ldots \ldots$ & $08 / 02 / 90$ & $17 / 01 / 91$ \\
\hline $8 \ldots \ldots \ldots \ldots \ldots$ & $19 / 03 / 90$ & $28 / 01 / 91$ \\
\hline $9 \ldots \ldots \ldots \ldots \ldots$ & - & 04/03/91 \\
\hline
\end{tabular}

(MV) e o número (NV) de vagens e a massa seca da parte aérea (MSPA) por planta e o índice de colheita (IC), que é a relação entre a produção de vagens e a produção de biomassa [IC $=\mathrm{MV} /(\mathrm{MV}+\mathrm{MSPA})]$. A seguir, amostraram-se cem gramas de vagens, determinando-se a massa total de grãos e de cem grãos (MCG), a partir do que se calculou o rendimento (RG) - a relação entre a massa de grãos sobre a massa de vagens da qual foram eles obtidos e expressa em grama de grãos/quilograma de vagens. Nas subparcelas, em que a massa de vagens não atingiu cem gramas, utilizou-se, nas determinações, a quantidade de frutos existentes.

Efetuou-se a colheita por arrancamento manual e obteve-se a produção do amendoim (PV) nas subparcelas após a secagem das vagens ao sol, somando-se-lhe a massa das vinte plantas amostradas. Expressou-se a produção em quilograma de vagens/hectare.

Analisaram-se os dados estatisticamente, aplicando-se o teste $\mathrm{F}$ para os tratamentos. O estudo de 
regressão polinomial foi feito para as variáveis significativas em função da época de semeadura.

\section{RESULTADOS E DISCUSSÃO}

A produção de vagens, a massa seca da parte aérea e a massa e o número de vagens por planta, o rendimento de grãos, a massa de cem grãos e o índice de colheita dos quatro cultivares de amendoim foram significativamente influenciados pela época de semeadura em 1989/90 e 1990/91 (Quadro 2).

Os cultivares de amendoim apenas não mostraram diferenças significativas entre si quanto ao acúmulo de matéria seca da parte aérea em 1989/90 e quanto ao índice de colheita em 1990/91 (Quadro 2).
A interação entre cultivares e épocas de semeadura foi significativa para a produção de vagens e a massa de vagens por planta nos dois anos do estudo, não havendo, em 1990/91, interação somente para o índice de colheita (Quadro 2).

As curvas de regressão obtidas para massa seca da parte aérea por planta, número e massa de vagens por planta, produção de vagens, em função dos cultivares de amendoim e da época de semeadura, nos anos agrícolas 1989/90 e 1990/91, são apresentados nas Figuras 3 a 6 .

Nos dois anos de estudo, todas as variáveis apresentaram comportamento similar, obtendo-se os maiores valores para as semeaduras efetuadas nas primeiras oportunidades da implantação da cultura no ano agrícola. Semeaduras realizadas a partir de

Quadro 2. Resultados da análiseda variância das variáveis produção de vagens (PV), massa seca da parte aérea (MSPA), massa de vagens da planta (MV) número de vagens por planta (NV), massa de cem grãos (MCG), rendimento de grãos (RG) e índice de colheita (IC) de quatro cultivares de amendoim semeados em oito e nove épocas, respectivamente, nos anos agrícolas 1989/90 e 1990/91, em Adamantina (SP). Médias de seis repetições

\begin{tabular}{|c|c|c|c|c|c|}
\hline Variáveis & F época (é) & F cultivar (c) & F é x c & CV (é) & $\mathrm{CV}(\mathrm{c})$ \\
\hline \multicolumn{4}{|c|}{$1989 / 90$} & $\%$ & $\%$ \\
\hline PV ...................... & $78,42 * *$ & $12,87 * *$ & $2,23 * *$ & 15,95 & 23,48 \\
\hline MSPA .......... & $191,07 * *$ & $0,61 \mathrm{~ns}$ & $0,38 \mathrm{~ns}$ & 11,24 & 21,54 \\
\hline 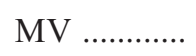 & $167,31 * *$ & $8,16^{* *}$ & $2,48 * *$ & 9,05 & 13,83 \\
\hline 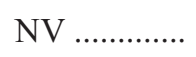 & $156,85^{* *}$ & $7,52 * *$ & $0,89 \mathrm{~ns}$ & 8,00 & 14,70 \\
\hline 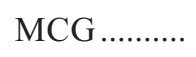 & $27,47 * *$ & $141,58^{* *}$ & $1,31 \mathrm{~ns}$ & 5,67 & 8,85 \\
\hline $\mathrm{RG} \ldots \ldots \ldots \ldots$ & $29,77 * *$ & $18,51 * *$ & $0,91 \mathrm{~ns}$ & 2,80 & 3,93 \\
\hline 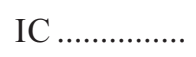 & $23,70 * *$ & $4,76^{* *}$ & $1,04 \mathrm{~ns}$ & 7,28 & 10,30 \\
\hline \multicolumn{6}{|c|}{ 1990/91 } \\
\hline 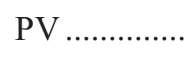 & $39,66^{* *}$ & $36,15^{* *}$ & $7,16^{* *}$ & 22,48 & 12,93 \\
\hline MSPA ......... & $35,70 * *$ & $9,41 * *$ & $3,00 * *$ & 6,39 & 7,81 \\
\hline 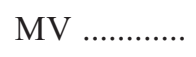 & $34,27 * *$ & $7,80 * *$ & $2,70 * *$ & 9,60 & 9,93 \\
\hline 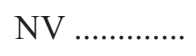 & $32,04 * *$ & $30,68 * *$ & $1,99 * *$ & 7,92 & 8,81 \\
\hline MCG ........... & $9,84 * *$ & $102,97 * *$ & $1,63 * *$ & 9,49 & 9,59 \\
\hline RG ................. & $10,05 * *$ & $52,54 * *$ & $1,73 * *$ & 3,76 & 4,53 \\
\hline IC ...................... & $17,23 * *$ & $2,28 \mathrm{~ns}$ & $1,57 \mathrm{~ns}$ & 10,77 & 10,40 \\
\hline
\end{tabular}

\footnotetext{
* Significativo ao nível de 5\%. ** Significativo ao nível de 1\%. ns: Não significativo. CV: Coeficiente de variação em porcentagem.
} 
novembro diminuíram, acentuadamente, os valores de todas as variáveis comparativamente àquelas efetuadas em épocas anteriores (Figuras 3 a 6).

Na Figura 1, encontram-se as médias quinzenais das temperaturas máximas, médias e mínimas do período experimental. A temperatura média, no decorrer dos experimentos, esteve entre o ideal de 22 a $28^{\circ} \mathrm{C}$, citado por Reichardt (1987). Verificam-se, contudo, temperaturas acima e abaixo desses limites nos períodos do estudo. Temperaturas médias máximas quinzenais acima de $30^{\circ} \mathrm{C}$ ocorreram de outubro a abril e as médias mínimas sempre foram menores do que $22^{\circ} \mathrm{C}$. As amplitudes entre as temperaturas médias, máximas e mínimas quinzenais nos dois anos podem ser consideradas semelhantes.

Comparando-se as temperaturas médias, máximas e mínimas, verifica-se que as ocorridas em 1990/91 foram superiores às de 1989/90 de setembro até janeiro (Figura 1).

É importante salientar que as chuvas ocorreram similarmente nos dois anos de experimentação. De novembro a março, houve a precipitação pluvial mais abundante (Figura 2) e as maiores temperaturas (Figura 1).

Pela Figura 3 - A e B - nota-se que a massa de matéria seca do amendoim em semeaduras anteriores a novembro de 1989/90 foi muito superior às do mesmo período em 1990/91. Enquanto em 1990/91 (B), obtiveram-se valores em torno de 20 a $30 \mathrm{~g}$ /planta, na média das variedades, em 1989/90 houve até cerca de $150 \mathrm{~g} /$ planta de acúmulo de matéria seca em função da época de semeadura. Deve-se salientar que os altos valores obtidos na primeira semeadura de 1989/ 90 para MSPA, MV e NV podem ser parcialmente explicados pelo baixo estande verificado nessa época. A menor competição entre as plantas amostradas para essas avaliações certamente aumentou essas variáveis, sem, contudo, causar, na mesma proporção, acréscimos na produtividade.

Esclarecidas as possíveis •discrepâncias relativas à primeira época de semeadura, observa-se que o maior acúmulo de matéria seca pelo amendoim em 1989/90 se deu com temperaturas médias entre 21 e $23^{\circ} \mathrm{C}$, com a média da máxima não ultrapassando $30^{\circ} \mathrm{C}$ e sendo a média da mínima menor que $15^{\circ} \mathrm{C}$ (Figura 1).

O resultado do acúmulo de matéria seca para época de semeadura a partir do início de novembro foi similar entre as variedades e entre os dois anos do estudo (Figuras 3 e 4), quando as temperaturas médias quinzenais estiveram acima de $23^{\circ} \mathrm{C}$ (Figura 1).

Esses resultados concordam com aqueles que verificaram diminuição da massa seca da parte aérea quando se aumentou a temperatura de 19 para $31^{\circ} \mathrm{C}$ (Ong, 1984), a temperatura média (Bolhuis \& Groot, 1959; Ketring, 1984) ou diferenças no acúmulo de matéria seca para épocas diferentes de semeadura (Zade et al., 1985).

Nas duas primeiras épocas de semeadura de cada um dos anos da experimentação, o cultivar Tatu mostrou o menor acúmulo de matéria seca, diferenciando, estatisticamente, dos outros três em 1990/91. Diferenças na produção de massa seca entre genótipos de amendoim foram constatadas por Zade et al. (1985).

A temperatura pareceu também influenciar o número (Figura 4 - A e B) e na massa (Figura 5 - A e B) de vagens por planta em razão da alta correlação entre tais variáveis com a massa seca da parte aérea dos cultivares de amendoim, obtendo-se, respectivamente, $\mathrm{r}=0,96 * *$ e $\mathrm{r}=0,98 * *$ para $1989 / 90 \mathrm{e}$ $\mathrm{r}=0,74 * *$ e $\mathrm{r}=0,92 * *$ para $1990 / 91$. A alta correlação verificada entre o número de vagens por planta $\mathrm{e}$ a massa de matéria seca do amendoim também foi obtida por Choudhari et al. (1985). A diminuição do número de vagens por planta tem sido relacionada ao aumento da temperatura média (Bolhuis \& Groot, 1959; Ketring, 1984) com os piores resultados a $33^{\circ} \mathrm{C}$ (Bolhuis \& Groot, 1959). Possíveis explicações podem estar relacionadas ao rápido alongamento da haste da planta, evitando que "pegs" tardios alcancem o solo para formar vagens (Leong \& Ong, 1983), à diminuição do número de "pegs" (Ketring, 1984) ou à diminuição da germinação dos grãos de pólen (Oakes, 1958). O maior número de vagens por planta já foi conseguido com temperaturas entre 27 e $30^{\circ} \mathrm{C}$ (Bolhuis \& Groots, 1959). 


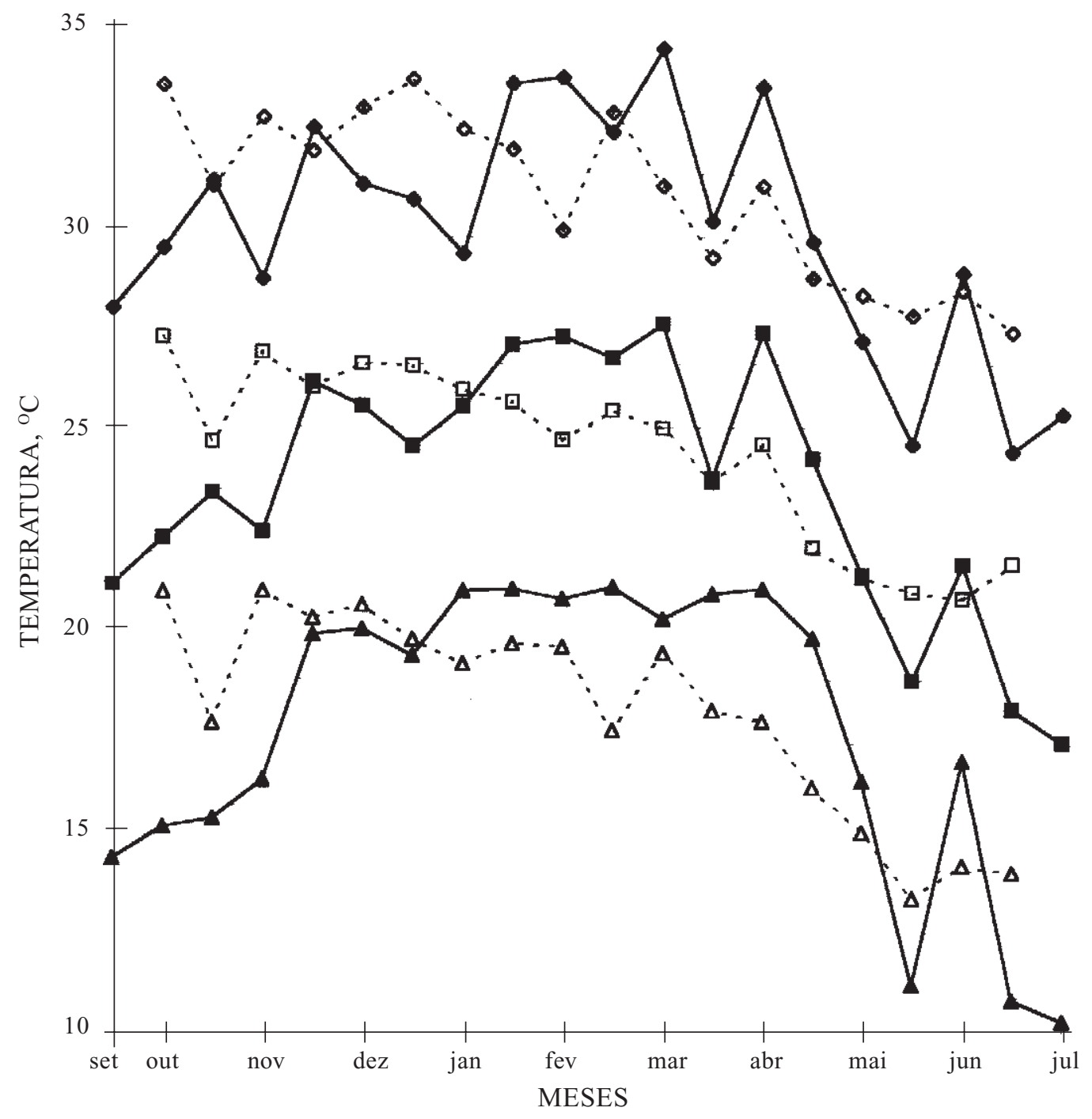

Figura 1. Médias quinzenais das temperaturas máximas, médias e mínimas no período experimental nos anos agrícolas 1989/90 e 1990/91, em Adamantina (SP). 


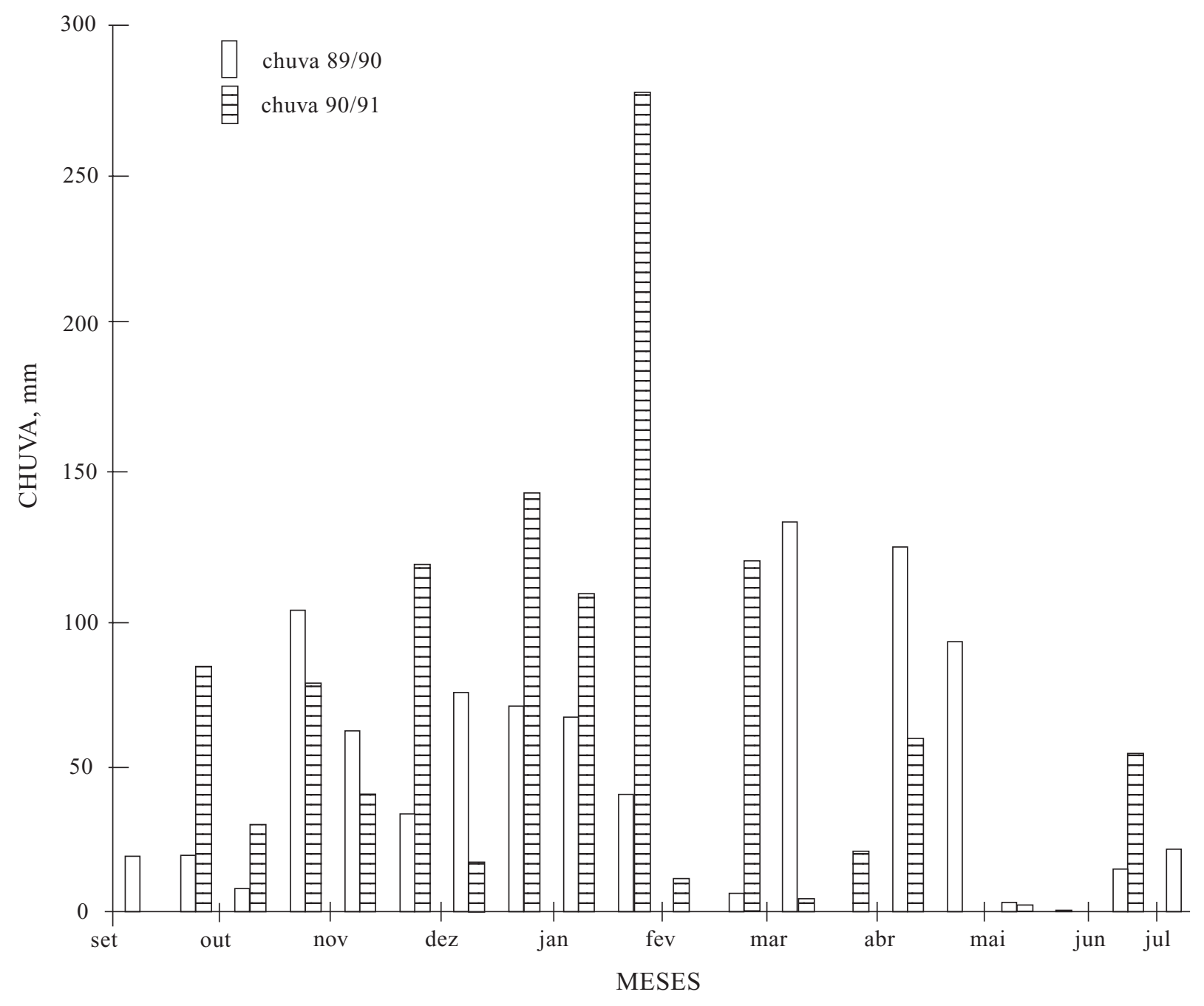

Figura 2. Chuvas acumuladas por quinzena no período experimental nos anos agrícolas 1989/90 e 1990/91, em Adamantina (SP). 


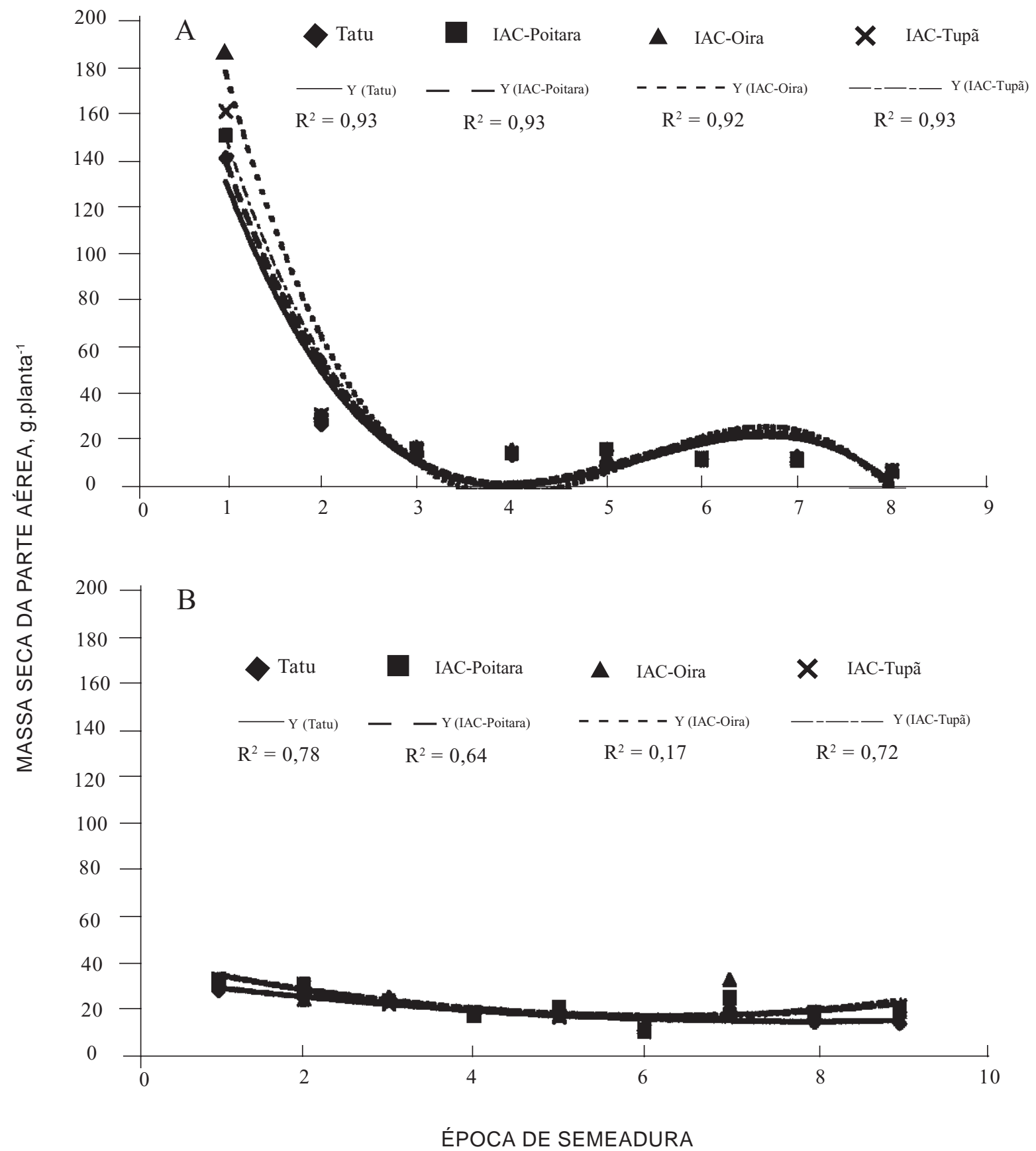

Figura 3. Massa seca da parte aérea na colheita dos cultivares de amendoim IAC-Oirã, IAC-Poitara, IAC-Tupã e Tatu semeados em Adamantina (SP). A: oito épocas no ano agrícola 1989/90; B: nove épocas no ano agrícola 1990/91. 


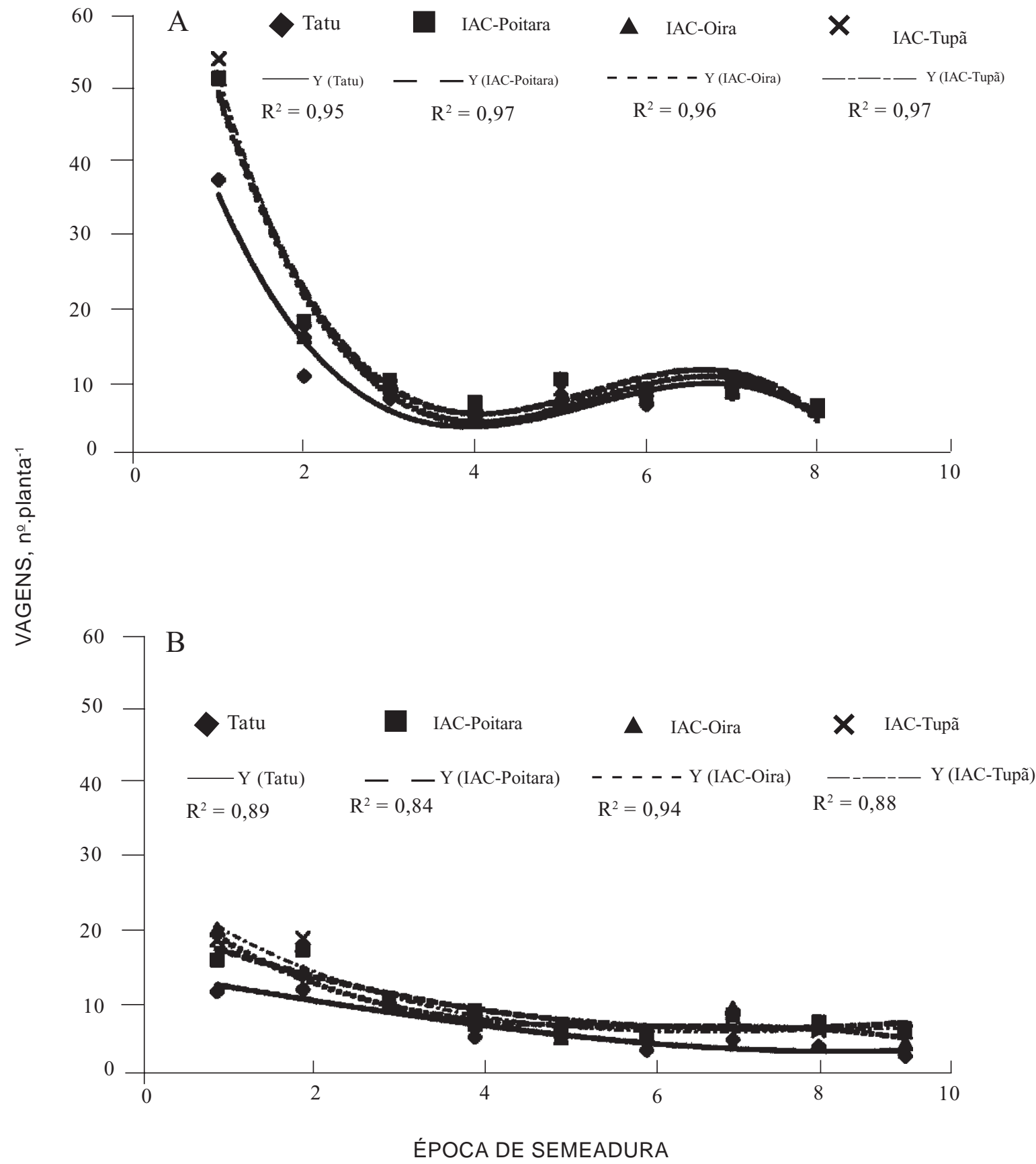

Figura 4. Número de vagens por planta dos cultivares de amendoim IAC-Oirã, IAC-Poitara, IAC-Tupã e Tatu em Adamantina (SP). A: oito épocas no anos agrícola 1989/90; B: nove épocas no ano agrícola 1990/91. 


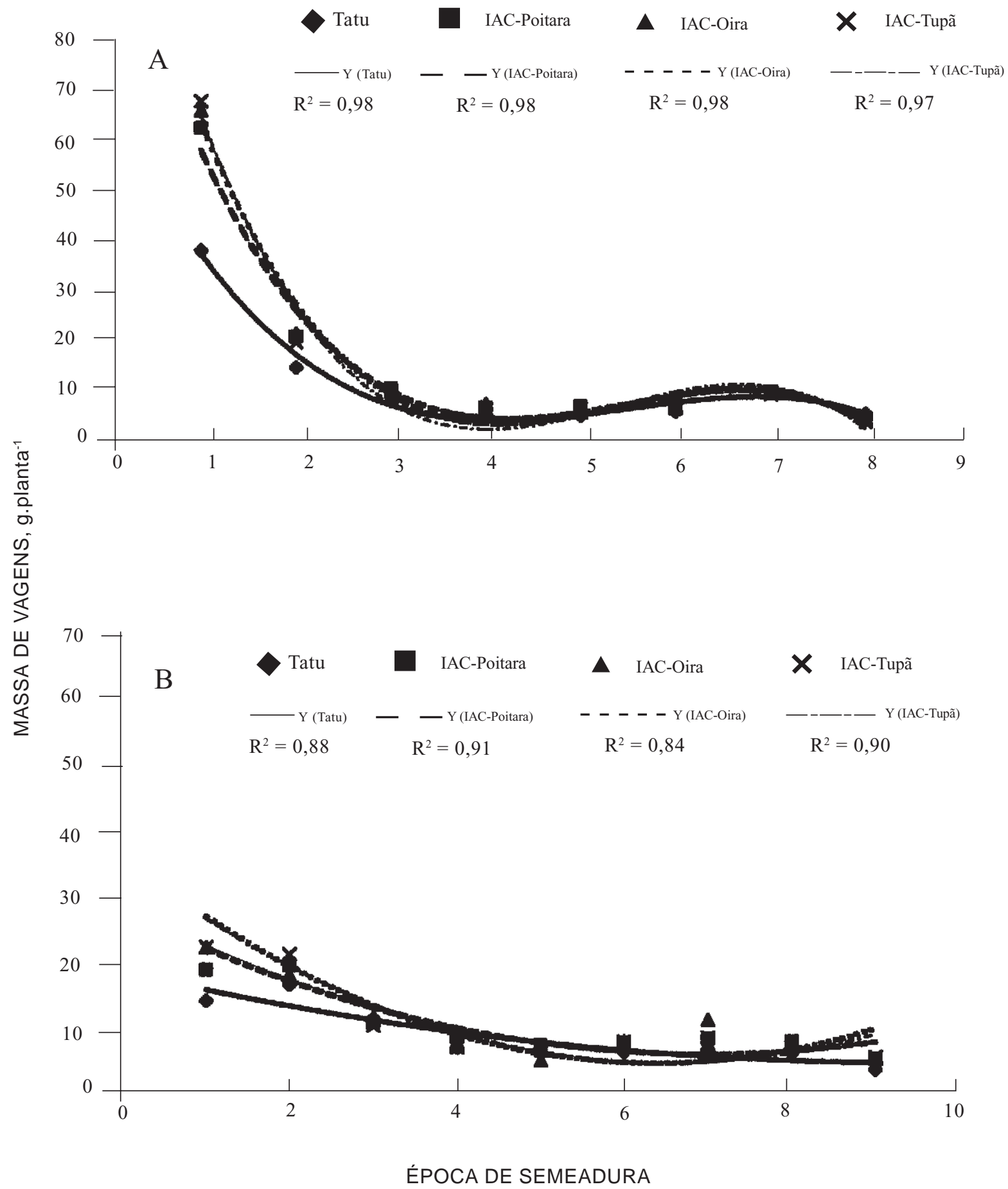

Figura 5. Massa de vagens dos cultivares de amendoim IAC-Oirã, IAC-Poitara, IAC-Tupã e Tatu semeados em Adamantina (SP). A: oito épocas no ano agrícola 1989/90. B: nove épocas no ano agrícola 1990/91. 


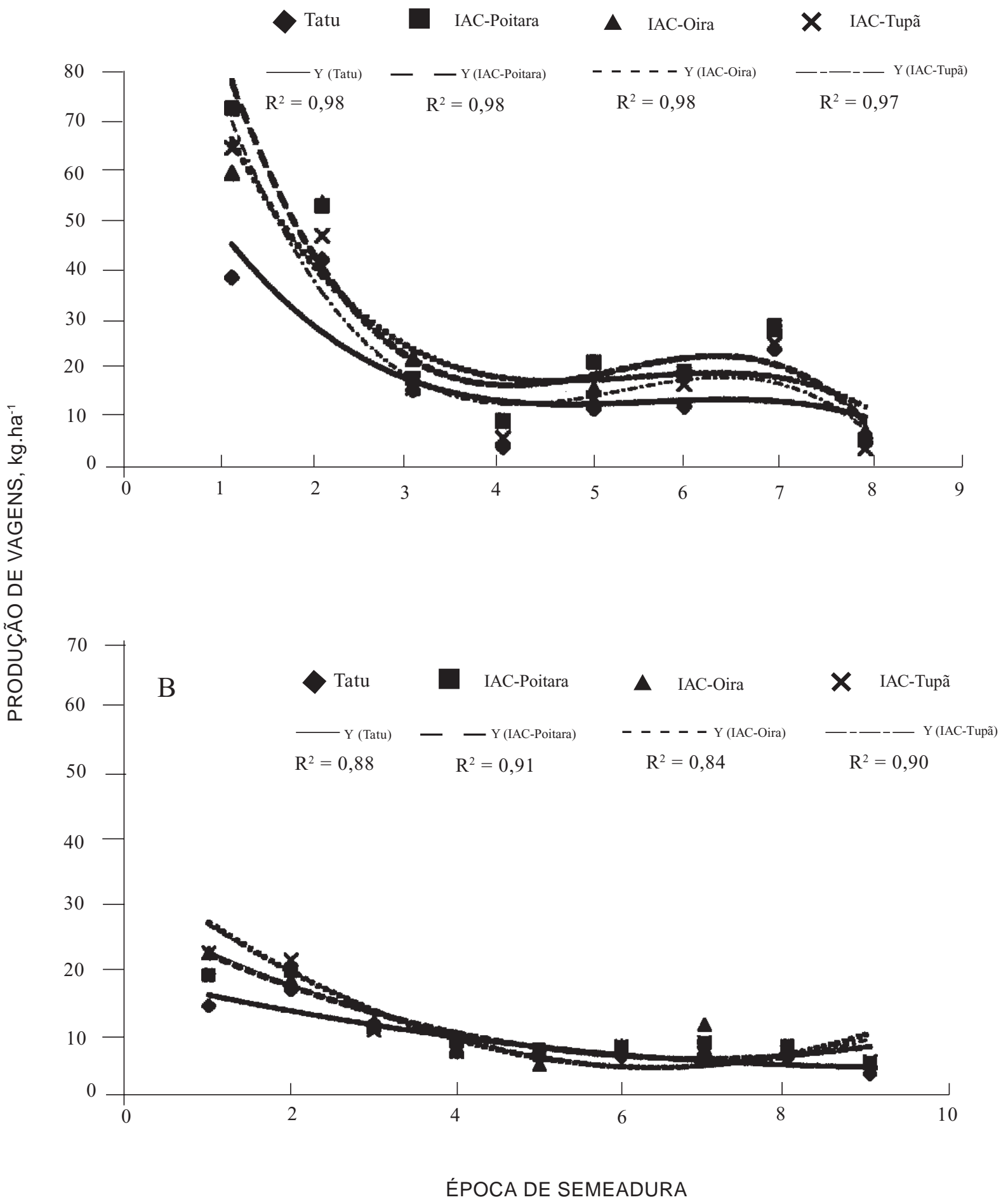

Figura 6. Produção de vagens dos cultivares de amendoim IAC-Poitara, IAC-Tupã e Tatu semeados em Adamantina (SP). A: oito épocas no ano agrícola 1989/90; B: nove épocas no ano agrícola 1990/91. 
A massa de vagens por planta (Figura 5 -A e B) diferiu entre as épocas de semeadura, como também observado por Zade et al. (1985).

A produção dos cultivares de amendoim foi resultante dos fatores de produção da massa e do número de vagens por planta. Os resultados deste estudo (Figura 6 - A e B) são concordantes com os de Smartt (1961, 1964) e Marenah \& Anderson (1977), os quais, na Rodésia e na Gâmbia respectivamente, obtiveram maiores produções nas semeaduras realizadas nas primeiras chuvas do ano agrícola. Concordam, ainda, com os de Wessling (1966) que, nas condições do Oeste paulista, observou as menores produções de amendoim do grupo Spanish-Valência, em semeaduras de março, e com os de Canecchio Filho (1955) na região de Campinas.

Os cultivares IAC-Oirã, IAC-Poitara, IAC-Tupã mostraram maior produção do que o Tatu, notadamente nas primeiras épocas de semeadura (Figura 6 A - B). A diferença na produção entre genótipos e variedades de amendoim tem sido relatada (Canecchio Filho, 1955; Wessling, 1966 ; Zade et al., 1985).

Nos experimentos, a época de semeadura não interferiu na população inicial de plantas por área; contudo, as produções das parcelas podem ser afetadas pela morte de plantas em razão da baixa disponibilidade de água (Canecchio Filho, 1955).

A influencia da época de semeadura sobre a massa de cem grãos e o rendimento (Quadro 2) pode estar relacionada ao regime hídrico (Pallas et al., 1979). O Tatu apresentou a menor massa de cem grãos, porém o maior rendimento, diferindo estatisticamente dos outros três. Segundo Pompeu (1987), a massa de cem sementes do Tatu é $50 \%$ menor do que a dos outros cultivares estudados.

Os menores índices de colheita (Quadro 2) foram obtidos nas primeiras épocas de semeadura em 1989/90, mas não no ano seguinte. As diferenças podem estar relacionadas às variações térmicas e hídricas ocorridas no desenvolvimento da cultura em cada época de semeadura. Variações no índice de colheita são explicadas pela competição existente entre os órgãos vegetativos e reprodutivos do amendoim (Choudhari et al., 1985).

\section{CONCLUSÕES}

1. As maiores produções do amendoim foram obtidas nas semeaduras entre a segunda quinzena de setembro e o mês de outubro.

2. A massa seca da parte aérea, a massa e o número de vagens por planta diminuíram, significativamente, quando se semeou a partir de novembro.

3. Os cultivares IAC-Oirã, IAC-Poitara e IACTupã, na melhor época de semeadura, foram mais produtivos que o Tatu, exibindo maior massa seca da parte aérea e maior massa e número de vagens por planta.

4. O Tatu foi o cultivar com o maior rendimento em grãos e a menor massa de cem grãos.

\section{REFERÊNCIAS BIBLIOGRÁFICAS}

BOLHUIS, G.G. \& GROOT, W. de. Observations on the effect of varying temperatures on the flowering and fruit set in three varieties of groundnut. Netherlands Journal Agricultural Science, Wageningen, 7:317-326, 1959.

CANECCHIO FILHO, V. Amendoim da sêca: épocas de plantio. Bragantia, Campinas, 14:XXIII-XXIV, 1955.

CHOUDHARI, S.D.; UDAYKUMAR, M. \& SASTRY, K.S.K. Physiology of bunch groundnuts (Arachis hypogaea). Journal of Agricultural Science, Cambridge, 104: 309$315,1985$.

GODOY, I.J. de; RODRIGUES FILHO, F.S. de O. \& GERIN, M.A.N. Amendoim. In: INSTITUTO AGRONÔMICO (Campinas). Instruções Agrícolas para o Estado de São Paulo. 3. ed. Campinas, 1986. p.23. (Boletim 200)

KETRING, D.L. Temperature effects on vegetative and reproductive development of peanut. Crop Science, Madison, 24:877-882, 1984.

LEONG, S.K. \& ONG,C.K. The influence of temperature and soil water deficit on the development and morphology of groundnut (Arachis hypogaea L.). Journal of Experimental Botany, Oxford, 34(148):1551-1561, 1983.

MARENAH, H.J. \& ANDERSON, A.K. Effect of variety, time of planting, spacing and fungicide on yield of groundnut in the Gambia. Oleagineux, Paris, 32(4):167-171, 1977. 
OAKES, A.J. Pollen behavior in the peanut (Arachis hypogaea L.). Agronomy Journal, Madison, 50:387-389, 1958.

ONG, C.K. The influence of temperature and water deficits on the partitioning of dry matter in groundnut (Arachis hypogaea L.). Journal of Experimental Botany, Oxford, 35(154):746-755, 1984.

PALLAS JUNIOR, J.E.; STANSELL, J.R. \& KOSKE,T.J. Effects of drought on Florunner peanuts. Agronomy Journal, Madison, 71:853- 858, 1979.

POMPEU, A.S. IAC-Oirã, IAC-Poitara, IAC-Tupã: novos cultivares de amendoim para o Estado de São Paulo. Bragantia, Campinas, 46(1):127-131, 1987.

REICHARDT, K. A água em sistemas agrícolas. São Paulo, Manole, 1987. p.157-188.
SMARTT, J. Factors influencing the selection and performance of groundnut varieties in Northern Rhodesia. Empire Journal of Experimental Agriculture, Oxford, 29(116): 299-306, 1961.

SMARTT, J. Factors influencing yield and quality of groundnut in Northern Rhodesia. Empire Journal of Experimental Agriculture, Oxford, 32(128):343-351, 1964.

WESSLING, W.H. Reaction of peanuts to dry and wet growing periods in Brazil. Agronomy Journal, Madison, 58:23-26, 1966.

ZADE, V.R.; DESHMUKH, S.N.; THOTE, S.G. \& REDDY, P.S. Influence of seasons on the expression of reproductive attributes in eight Spanish Bunch genotypes of groundnut (Arachis hypogaea L.). Oleagineux, Paris, 40(10):497-501, 1985. 